\title{
Infantile Scurvy: A Historical Perspective
}

\author{
Kumaravel Rajakumar, MD
}

\begin{abstract}
Scurvy, a disease of dietary deficiency of vitamin $C$, is uncommon today. Among diseases, scurvy has a rich history and an ancient past. The Renaissance (14th to 16th centuries) witnessed several epidemics of scurvy among sea voyagers. In 1747, James Lind, a British Naval surgeon, performed a carefully designed clinical trial and concluded that oranges and lemons had the most antiscorbutic effect. Eventually, with the provision of lemon juice to the sea voyagers, scurvy became rare at sea. Infantile scurvy appeared almost as a new disease toward the end of the 19th century. The increased incidence of infantile scurvy during that period was attributed to the usage of heated milk and proprietary foods. Thomas Barlow described the classic clinical and pathologic features of infantile scurvy in 1883. Between 1907 and 1912, Holst and Frolich induced and cured scurvy in guinea pigs by dietary modification. In 1914, Alfred Hess established that pasteurization reduced the antiscorbutic value of milk and recommended supplementation of fresh fruit and vegetable juices to prevent scurvy. Such pioneering efforts led to the eradication of infantile scurvy in the United States. A brief history of infantile scurvy is provided. Pediatrics 2001;108(4). URL: http:// www.pediatrics.org/cgi/content/full/108/4/e76; scurvy, infantile scuroy, history, nutrition.
\end{abstract}

S curvy, as a disease entity, has an impressionable and indelible history in the annals of medicine. The review of recorded history suggests scurvy to be an ancient disease. Medical writings from antiquity to the Middle Ages describe the classic signs and symptoms of scurvy. Critical appraisal of such literature raises the question of whether other diseases were mistaken for scurvy. ${ }^{1}$ The Renaissance witnessed an unprecedented sense of adventurism and exploration by sea. The early sea voyages were often prolonged and lacked adequate supplies of fresh fruits, vegetables, or animal foods. Such dietary deprivations led to explosive outbreaks of scurvy among the sailors and to the eventual failure of many expeditions.

\section{EARLY HISTORY OF SCURVY}

One of the earliest outbreaks of scurvy at sea was sustained by the crew of Vasco da Gama during his 1497 expedition to India. ${ }^{2}$ Da Gama began his expedition from Lisbon on July 9, 1497, with a fleet of 4 ships and a crew of 140 men. It took them 6 months

From the Department of Pediatrics, University of Pittsburgh School of Medicine, Children's Hospital of Pittsburgh, Pittsburgh, Pennsylvania. Received for publication Mar 9, 2001; accepted May 15, 2001.

Address correspondence to Kumaravel Rajakumar, MD, Children's Hospital of Pittsburgh, General Academic Pediatrics, 3705 Fifth Ave, Pittsburgh, PA 15213-2583. E-mail: rajakuk@chplink.chp.edu

PEDIATRICS (ISSN 0031 4005). Copyright (C) 2001 by the American Academy of Pediatrics. to round the Cape of Good Hope. By the time da Gama's crew landed on the southeast coast of Africa, most of them were afflicted with scurvy. Da Gama recorded: "Many of our men fell ill here, their feet and hands swelling, and their gums growing over their teeth so that they could not eat." 2 As they sailed farther up the east coast of Africa, they met local traders, who traded them fresh oranges. Within 6 days of eating the oranges, da Gama's crew recovered fully and he noted, "It pleased God in his mercy that ... all our sick recovered their health for the air of the place is very good." 2

From India, da Gama returned across the Arabian Sea. Within 12 weeks of sailing, his crew was again afflicted and weakened by scurvy. Da Gama commented: "We addressed vows and petitions to the Saints ... it pleased God in his mercy to send us a wind which in the course of six days, carried us within sight of land ... at this we rejoiced as ... we hoped to recover our health there as we had done before ... the Captain-Major sent a man on shore to bring off a supply of oranges which were much desired by our sick." 2 Da Gama lost more than half of his crew by the end of his journey. His crew sustained scurvy when they had been at sea for 10 weeks or more. They recognized oranges to be an effective antiscorbutic by the second outbreak. The experience of da Gama in dealing with scurvy did not become common knowledge, and over the next several centuries, scurvy remained as the scourge of the sea explorers.

James Lind's experiment to test the potency of various antiscorbutic remedies is an important milestone in the history of scurvy. ${ }^{3}$ Lind performed his famous experiment in 1747 while a naval surgeon aboard the British naval ship Salisbury. ${ }^{4}$ He chose 12 patients with severe scurvy and housed them in a sick bay. The basic diet was similar for all the patients. The 12 men were divided into 6 groups and each group was given a different remedy. The antiscorbutic remedies tested were cider, elixir of vitriol, vinegar, seawater, 2 oranges and 1 lemon for 6 days, and a medicinal paste made of nutmeg and a variety of other ingredients. The patients receiving the oranges and lemons made a remarkable recovery and were well in 6 days and were appointed to nurse the rest of the sick. Lind was able to conclude that citrus fruits had the most effective antiscorbutic potency. It took another 50 years before the British navy made the provision of lemon juice routine onboard. 2,3 Such a measure resulted in a sharp decline of scurvy among the British naval sailors.

As scurvy was becoming rare at sea during the 
19th century, an "epidemic" of land scurvy was witnessed. ${ }^{1,2,5}$ The populations of the Great Potato Famine, the armies of the Crimean war and American civil war, the Arctic explorers, and the California gold rush communities were all prominent victims of scurvy on land..$^{2,6}$ It was indeed unfortunate that the knowledge gained in conquering "sea scurvy" did not translate in the avoidance of land scurvy. Toward the end of the 19th century, on the heels of land scurvy arrived "infantile scurvy," as a new disease, often affecting the affluent infant subsisting on a diet of proprietary foods and heated milk.

\section{INFANTILE SCURVY: A BRIEF HISTORY}

Francis Glisson, a Cambridge professor, made one of the earliest recorded descriptions of infantile scurvy. In his famous treatise on rickets, published in 1650, he referred to scurvy occurring conjointly with rickets: "Scurvy is sometimes conjoyned with this Affect (rickets). It is either hereditary, or perhaps in so tender a Constitution contracted by infection, or lastly, it is produced from the indiscreet and erroneous regiment (diet) of the Infant, and chiefly from the inclemency of the Ayr (air) and Climate where the Child is educated."7

During the next 200 years, the literature is devoid of references to the occurrence of infantile scurvy. The lack of reporting of infantile scurvy after the Glisson era probably reflects a true diminished occurrence of scurvy. The advances in agriculture witnessed during the 18th century had an impact on the occurrence of scurvy. The concept of "market gardening" close to urban areas increased the supply and consumption of fresh vegetable produce. ${ }^{8}$ The adoption of potato as a staple and as a weaning food for infants during the 18th century ensured the adequacy of dietary intake of vitamin C. The practice of prolonged breastfeeding during the 17th and 18th centuries protected the infants from developing scurvy. ${ }^{9}$ Incidentally, with the introduction of proprietary foods during the middle of the 19th century for infant feeding, infantile scurvy emerged as a "new" disease.

Clinicians failed to recognize infantile scurvy as a separate disease entity and mislabeled it "acute rickets." ${ }^{\prime 9}$ During the 19th century, rickets was a prevalent chronic morbid condition among infants. As infantile scurvy was a relatively rare condition and was often engrafted on to preexisting rickets, it was understandable why it was misconstrued to be acute rickets. The acute rickets confusion lasted until Dr Thomas Barlow clarified the true nature of infantile scurvy in $1883 .{ }^{10}$

In 1875, Dr Thomas Smith of the Hospital for Sick Children, Great Ormond Street, London, mistakenly described a case of infantile scurvy as "hemorrhagic periostitis."10,11 Dr Barlow was a registrar under Dr Smith and had performed the autopsy on the case described as hemorrhagic periostitis. According to Barlow, the diagnosis of infantile scurvy was considered by Dr Smith but dismissed, as the infant had no gum involvement. ${ }^{10}$

W. B. Cheadle, a pediatrician at the Hospital for Sick Children, described 3 cases of scurvy in
1878. ${ }^{10,11}$ Cheadle's patients were between 16 months to 3 years in age and all of them had rickets. Cheadle had accurately analyzed the diets of these children and wrote, "The diet was, however, more than a rickety diet-it was a scurvy diet."12 The typical weaning diet of those days included potatoes and gravy, as meat was expensive. Unlike patients with just rickets, these 3 cases of scurvy with rickets lacked potatoes and fresh milk in their diet. Cheadle cured the scurvy of his patients by feeding them raw meat, fresh milk, and mashed potatoes mixed with milk.

In 1881, Dr Samuel Gee of St Bartholomew's Hospital, London, mistook 5 cases of infantile scurvy to be cases of "osteal or periosteal cachexia."10,11 Dr Cheadle was able to relate to the cases described by Dr Gee and concluded that those were cases of scurvy supervening on rickets precipitated by a "scurvy diet."13

Dr Thomas Barlow, an assistant physician at the Hospital for Sick Children, established the true nature of infantile scurvy. In 1883, Barlow studied 31 cases of acute rickets: 11 were his patients, 19 were from the published literature, and 1 was a case history communicated to him. ${ }^{10}$ By clinical and pathologic analysis he concluded that the cases described as "acute rickets" were indeed a combination of scurvy and rickets, but with scurvy as an essential element and rickets as a variable element. To this day, Barlow's clinical description of infantile scurvy, with the appropriate pathologic correlation remains a classic. Barlow stated that the extreme pain and tenderness seen in the cases of infantile scurvy reflected bone pathology. ${ }^{10}$ By postmortem studies, Barlow established that subperiosteal hemorrhage was the anatomic basis for limb affection in infantile scurvy. Barlow implicated the diet as an etiologic factor. His antiscorbutic regimen included raw-meat juice, fresh milk, orange juice, and access to as much fresh air as possible. He ventured to state that proprietary "infant foods" could not be trusted as "sole aliment for any lengthened period, however useful they may be as adjuncts." 10 Soon infantile scurvy became a recognizable entity and was referred to as "Barlow's disease." By the end of the 19th century, infantile scurvy was readily recognized and was being frequently observed in the United States and Great Britain.

\section{INFANTILE SCURVY IN THE UNITED STATES}

In 1889, Dr Northrup, of New York, had seen a case of infantile scurvy. His failure to diagnose the condition resulted in the death of the infant. $\mathrm{He}$ realized the true nature of the infant's illness on postmortem examination. That was the first case of infantile scurvy recorded in the medical literature of the United States. ${ }^{14}$ By 1894, Northrup had collected 114 cases of infantile scurvy and reported them at a meeting of the New York Academy of Medicine. He had observed that "use of proprietary foods and condensed milk produces more scurvy than all other causes combined." 14

L. Emmett Holt's descriptions of scurvy in his 1897 textbook illustrate the advances in understanding of the clinical presentations of infantile scurvy. ${ }^{15}$ Holt 
classified infantile scurvy into 3 clinical types: a fatal severe form, a severe form culminating in full recovery on identification and treatment, and a mild form without gum involvement or limb swellings. According to Holt, the mild version of infantile scurvy was perhaps the most common, and was often not recognized because of lack of classic gum involvement. Holt, in his discussions on the causes of infantile scurvy, refers to the use of heated infant formulas and concluded that it was the faulty formula and not the process of heating, which caused infantile scurvy. Holt concluded, "proprietary infant-foods are most certain to produce scurvy, when they form the exclusive diet." 15

As infantile scurvy became more prevalent, a collective investigation of the problem was conducted by the American Pediatric Society in $1898 .{ }^{16}$ A total of 379 cases were collected and analyzed. Most of the patients in this series were white and were between the ages of 7 and 14 months. Most patients were from a well-to-do background. Dietary history was available for 356 cases. Proprietary foods were part of the diet of 214 patients. Sterilized, pasteurized, or condensed milk had been given to 165 cases.

The members of the research committee concluded that most patients had received proprietary foods and that prolonged usage of unsuitable foods led to the development of scurvy. Tentative as these conclusions were, 1 of the committee members disagreed and a minority report was added. In the minority report "chronic ptomaine poisoning" attributable to absorption of toxins was considered to cause scurvy, and sterilizing, pasteurizing, or cooking of the milk were not implicated in the causation of scurvy. These conclusions reflect the confusion regarding the causation of scurvy in the minds of the American pediatricians of that era.

\section{CAUSE OF INFANTILE SCURVY}

Without doubt, the explosive increase of infantile scurvy during the latter part of 19th century coincided with the advent of usage of heated milks and proprietary foods. ${ }^{17}$ Bacterial contamination of raw milk was responsible for significant mortality and morbidity among infants during that time. ${ }^{2}$ Usage of heated milk led to noticeable decline in infant mortality. The advent of heated milks was heralded as a great advance in infant feeding. Unfortunately, the process of heating the milk led to loss of vitamin C. Exclusive usage of heated milks with no other antiscorbutic supplementation led to the development of scurvy. Proprietary foods were touted as being comparable to breast milk in infant feeding. Being farinaceous and of poor nutritional quality, they were a poor substitute for breast milk. They were extensively adopted by the well-to-do. Such indiscreet use of wealth led to increased incidence of scurvy among infants from higher socioeconomic strata.

\section{CONCLUSION}

The eventual solving of the malady of infantile scurvy can be tied to the monumental work of Holst and Frolich. ${ }^{18,19}$ Between 1907 and 1912, they induced and cured scurvy in guinea pigs by dietary modification. Guinea pigs exposed to a diet of cereal grains developed scurvy. Addition of fruits, fresh vegetables, or their juices to the grains prevented the occurrence of scurvy in guinea pigs. Their study was instrumental for several advances in the understanding of etiology and treatment of scurvy. ${ }^{20}$

In 1914, Alfred Hess, a pediatrician at the Hebrew Asylum in New York, had noted several cases of scurvy among infants fed on pasteurized milk. ${ }^{21}$ The increased incidence of infantile scurvy at the Hebrew Asylum had coincided with the elimination of orange juice from the diet. The New York Milk Commission was of the opinion that pasteurized milk heated to $145^{\circ} \mathrm{F}$ retained its chemical constituents. On the basis of such an assumption, orange juice was excluded from the infants' diet. Hess was able to effect a cure for scurvy by providing raw milk or orange juice or potatoes. His experiments clearly established that pasteurization resulted in the loss of antiscorbutic potency of milk. Hess recommended that infants receiving heated formulas be supplemented with fresh fruit or vegetable juices to prevent scurvy. Such advances in the understanding of scurvy led to the eventual eradication of infantile scurvy.

\section{REFERENCES}

1. Hirsch A. Handbook of Historical and Geographical Pathology. Vol. 2. London, England: New Sydenham Society; 1885:507-568

2. Carpenter KJ. The History of Scuroy and Vitamin C. Cambridge, England: Cambridge University Press; 1986

3. Lorenz AJ. The Conquest of Scuroy. Essays on History of Nutrition and Dietetics. Chicago, IL: American Dietetic Association; 1967:97-102

4. Stewart CP, Guthrie D, eds. Lind's Treatise on Scuroy. [A bicentenary volume containing a reprint of the first edition of A Treatise of the Scurvy by James Lind]. Edinburgh, Scotland: Edinburgh University Press; 1953:145-146

5. Hess AF. Scuroy Past and Present. Philadelphia, PA: JB Lippincott Company; 1920

6. Jacob RA. Three eras of vitamin C discovery. Subcell Biochem. 1996;25: $1-16$

7. Ruhrah J. Pediatrics of the Past. New York, NY: Paul B. Hoeber, Inc; 1925:272-273

8. Lomax E. Difficulties in diagnosing infantile scurvy before 1878. Med Hist. 1986;30:70-80

9. Still GF. Infantile scurvy: its history. Arch Dis Child. 1935;10:211-218

10. Barlow T. On cases described as 'acute rickets' which are probably a combination of scurvy and rickets, the scurvy being an essential, and rickets a variable, element. Med Chir Trans (London). 1883;66:159-220

11. Wilson LG. The clinical definition of scurvy and the discovery of vitamin C. J Hist Med. 1975;30:40-60

12. Poynton FJ. Dr Cheadle and infantile scurvy. Arch Dis Child. 1935;10: 219-222

13. Cheadle WB. Osteal or periosteal cachexia and scurvy. Lancet. 1882;2: 48-49

14. Northrup WP, Crandall FM. Scorbutus in infants. $N$ Y Med J. 1894;59: 641-646

15. Holt EL. The Diseases of Infancy and Childhood. New York, NY: D. Appleton \& Co; 1897:209-215

16. Griffith JPC, Jennings CG, Morse JL. The American Pediatric Society's collective investigation on infantile scurvy in North America. Arch Pediatr. 1898;15:481-508

17. Wood AL. The History of Artificial Feeding of Infants. Lydia J. Robert Award Essays. Chicago, IL: The American Dietetic Association; 1968:21-29

18. Holst A. Experimental studies relating to "ship-beri-beri" and scurvy. I. Introduction. J Hyg (Cambridge). 1907;7:619-633

19. Holst A, Frolich T. Experimental studies relating to ship beri-beri and scurvy. II. On the etiology of scurvy. J Hyg (Cambridge). 1907;7:634-671

20. Mc Collum EV. A History of Nutrition. Cambridge, MS: Riverside Press; 1957:252-265

21. Hess AF, Fish M. Infantile scurvy: the blood, the blood-vessels and the diet. Am J Dis Child. 1914;8:385-405 